Volume 8. No. 9, September 2020

International Journal of Emerging Trends in Engineering Research

Available Online at http://www.warse.org/IJETER/static/pdf/file/ijeter132892020.pdf

https://doi.org/10.30534/ijeter/2020/132892020

\title{
The Method of Increasing Resolution in Network of Radars type as AN/TPQ-49
}

\author{
Hennadii Khudov ${ }^{1}$, Bogdan Lisogorsky ${ }^{2}$, Serhii Sokolovskyi ${ }^{3}$, \\ Anatolii Ostrovskyi ${ }^{4}$, Vitalii Losa ${ }^{5}$, Irina Khizhnyak ${ }^{6}$ \\ ${ }^{, 1}$ Department of Radar Troops Tactic, Ivan Kozhedub Kharkiv National Air Force University, Kharkiv, Ukraine, \\ 2345kh_hg@ukr.net \\ ${ }^{, 2}$ Department of Radar Troops Tactic, Ivan Kozhedub Kharkiv National Air Force University, Kharkiv, Ukraine, \\ 2345kh_hg@ukr.net \\ ${ }^{3}$ Department of Artillery Reconnaissance Systems and Instruments, Hetman Petro Sahaidachnyi National Army \\ Academy, Lviv, Ukraine, 2345kh_hg@ukr.net \\ ${ }^{4}$ Technical Support Department, Ivan Cherniakhovskyi National Defence University, Kyiv, Ukraine, \\ 2345kh_hg@ukr.net \\ ${ }^{2}$ Research Center, Military Institute of Taras Shevchenko Kyiv National University, Kyiv, Ukraine, \\ lozich@ukr.net
}

\begin{abstract}
The subject matter of the paper is the method of increasing resolution in network of radars type as AN/TPQ-49. The goal is the statistical simulation of trajectory measurements in a multi-station radar complex of counter-battery. The tasks are the determination of the accuracy of measuring the location of fire firing means. The accuracy of measuring the location of fire firing means was determined. For a given location of fire firing means, the parameters of the trajectory of the object (mines, projectile) of the fire firing means were calculated when firing at a specific target. Using the developed approaches, it is possible to determine the trajectory measurement matrix taking into account the measurement errors of the object coordinates (mines, projectile) on the trajectory at different reception points of the multi-position radar complex of the counter-battery combat.
\end{abstract}

Key words: method, increasing resolution, network of radars, target.

\section{INTRODUCTION}

According to the analysis of statistical data of the International Institute for Counter-Terrorism, the most common types of terrorist attacks are attacks using small arms and grenade launchers and mortar shelling [1]. The use of mortars by terrorists is due to the following [1]:

- at first, mortars are quite easy to make by hand from improvised materials;

- the second, terrorists often place mortar firing positions in residential areas, refugee camps, near schools, hospitals, under the guise of a "human shield"; - the third, regular mortar shelling has a very strong psychological impact.

The experience of recent armed conflicts shows the growing role of counter-battery radars, which allow units on the line of demarcation of troops to obtain a variety of information about the nature of the enemy's actions [2]-[3].

For example, the main disadvantage of small light portable radar counterbattery AN/TPQ-49 is a fairly wide beam pattern of the antenna in azimuth (the width of the azimuth pattern at $3 \mathrm{~dB}$ is about $19^{0}$ [4]), and in the angular plane. This is due to the need (equivalent to paying for other benefits) to provide other benefits of this radar, such as small size, light weight, ease of transport, electronic circular scanning (no mechanical rotation of the antenna) and the use of decimetre wavelength range (L-range, $23 \mathrm{~cm}$ ), which provides high reliability of the radar and ease of using. The presence of wide rays of the radiation pattern in the azimuthal plane necessitates the use of a monopulse (sum-difference) method of determining the azimuth, which leads to the presence of known problems [5]-[16]:

- the deterioration of resolution in angular coordinates;

- the distortion of the direction finding characteristic of the monopulse system and increase of angular measurement errors in the presence of two or more targets in the main beam of the antenna pattern.

Given the rather wide rays of the antenna pattern, the probability of getting into the main ray of the pattern of other targets and local objects that interfere with the tracking of the target becomes quite high. This leads to significant errors in the measurement of the azimuth of the target, and deterioration of the accuracy of determining the coordinates of the firing point.

\subsection{Problem analysis}

The known methods of improving the resolution of the angular coordinates are to increase the size of the antennas or the transition to a range of shorter wavelengths [17]-[20]. In the case of radars with electronic scanning type AN/TPQ-49, the first and second path is impractical because: 
- the first way leaves the radar such advantages as small size, ease and convenience of transportation;

- the second way leaves the radar such an advantage as reliability in operation and ease of adjustment after transportation.

An alternative possible way to increase the resolution of angular coordinates and reduce the impact of interfering targets on the determination of angular coordinates is the using of system effects in the joint processing of radar information from several spatially spaced radars [6]-[7], [11], [13]-[14], [16]-[22].

Therefore, the task of increasing the resolution and reducing the impact of interfering targets on the accuracy of determining the angular coordinates of the accompanying target, without changing the weight and size and performance characteristics of the radar type AN/TPQ-49, is relevant. The purpose of the paper is to develop a method to increase the resolution and reduce the impact of interfering objects on the accuracy of determining the angular coordinates of the target, without changing the mass and size and performance characteristics of the radar type AN / TPQ-49.

\section{MAIn Material}

When using the monopulse method of determining the angular coordinates, the presence in the main beam of the pattern of the antenna of the second target leads to an increase in the targeting error of the first target, which is located in the equal signal direction (ESD). When using the amplitude total-difference direction-finding system, the magnitude of this error is determined by expression (1) $[4]$ :

$$
\Delta \theta=-\frac{\alpha^{2}}{\mu} \frac{F^{2}\left(\theta_{0}-\theta_{2}\right)+F^{2}\left(\theta_{0}+\theta_{2}\right)}{4 F^{2}\left(\theta_{0}\right)},
$$

where $\Delta \theta-$ the target direction error, which is located on the ESD; $\theta_{2}$ - the angle of the second target relative to the ESD; $\alpha=\frac{E_{m 2}}{E_{m 1}}-$ the ratio of the amplitudes of the echo signals from the targets; $\mathrm{E}_{\mathrm{m} 1,} \mathrm{E}_{\mathrm{m} 2}$ amplitudes of echo signals reflected from the first and second targets; $\mu$-direction finding sensitivity around ESD; $F\left(\theta_{0}\right)$ - antenna pattern; $\theta_{0}$ - the angle of deviation of the maximum of the antenna pattern from the ESD; $F\left(\theta_{0}-\theta_{2}\right), F\left(\theta_{0}+\theta_{2}\right)$ - directivity diagram of the first and second channels.

When using a phase total-difference direction-finding system, the error is determined by the expression:

$$
\Delta \theta_{\phi}=\frac{\alpha^{2}}{\mathrm{k}_{\lambda} 1} \frac{\mathrm{F}^{2}\left(\theta_{2}\right)}{\mathrm{F}^{2}(0)} \sin \left(\mathrm{k}_{\lambda} 1 \sin \left(\theta_{2}\right)\right),
$$

where $\mathrm{k}_{\lambda}=\frac{2 \pi}{\lambda}$ is the wave number; $1-$ the distance between the phase centres of the first and second channels; $\alpha$-the ratio of the amplitudes of the reflected signals. The influence of the presence of the second target in the beam of the antenna directivity diagram on the error of determining the bearing of the first target for the amplitude sum-difference system is shown in Figure 1.

ESD

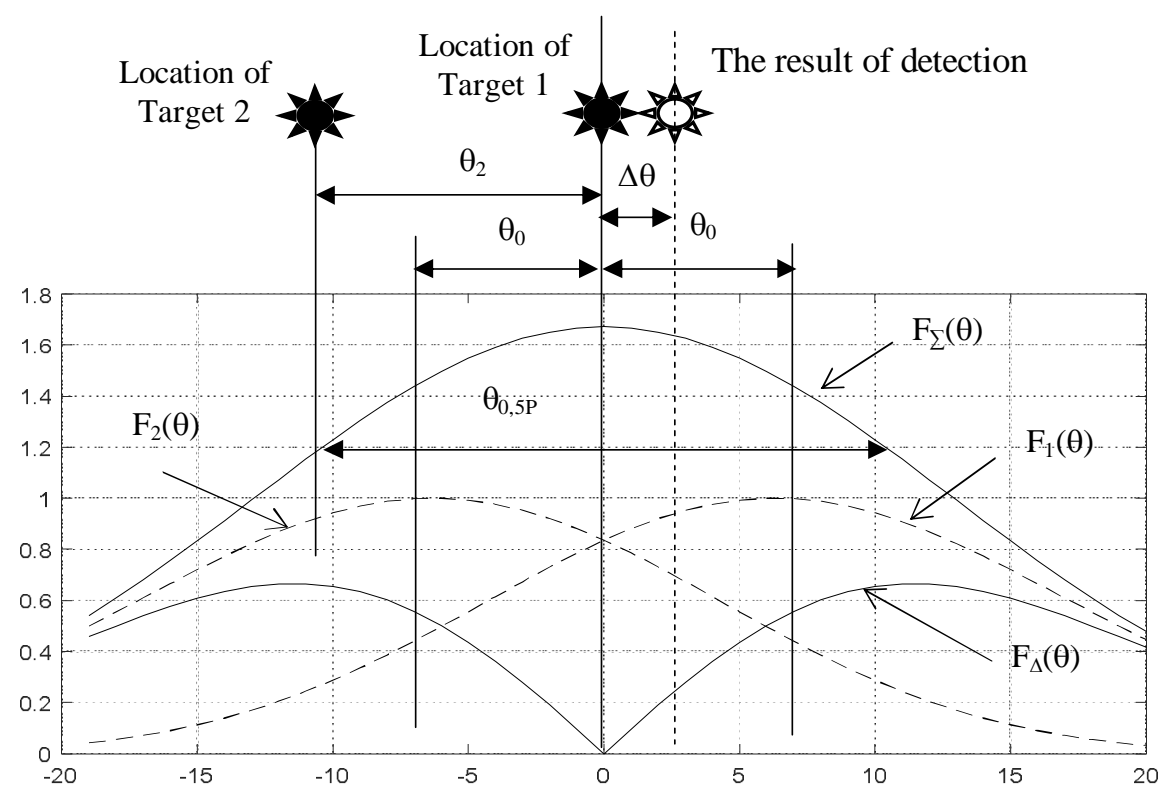

Figure 1 : The effect of the presence of the second target on the error of determining the azimuth of the target on the ESD 
In Figure 1 shows that in the presence of two targets in the beam, where Target 1 is located on the ESD, and Target 2 is located at an angle $\theta_{2}$, only one target will be detected at an angle $\Delta \theta$.

The results of measuring the azimuth of the target, which is located on the ESD, in the presence of the second target in the beam are shown in Figure 2, where the dots indicate the positions of the targets, and the cross indicates the result of detection. In Figure 2 shows that when the targets are not separated by azimuth, the distance of Target 2 from the ESD leads to an increase in the error of determining the azimuth of Target 1 , which is located on the ESD.

The dependence of the azimuth measurement error of the first target on the position of the second target is shown in Figure 3..
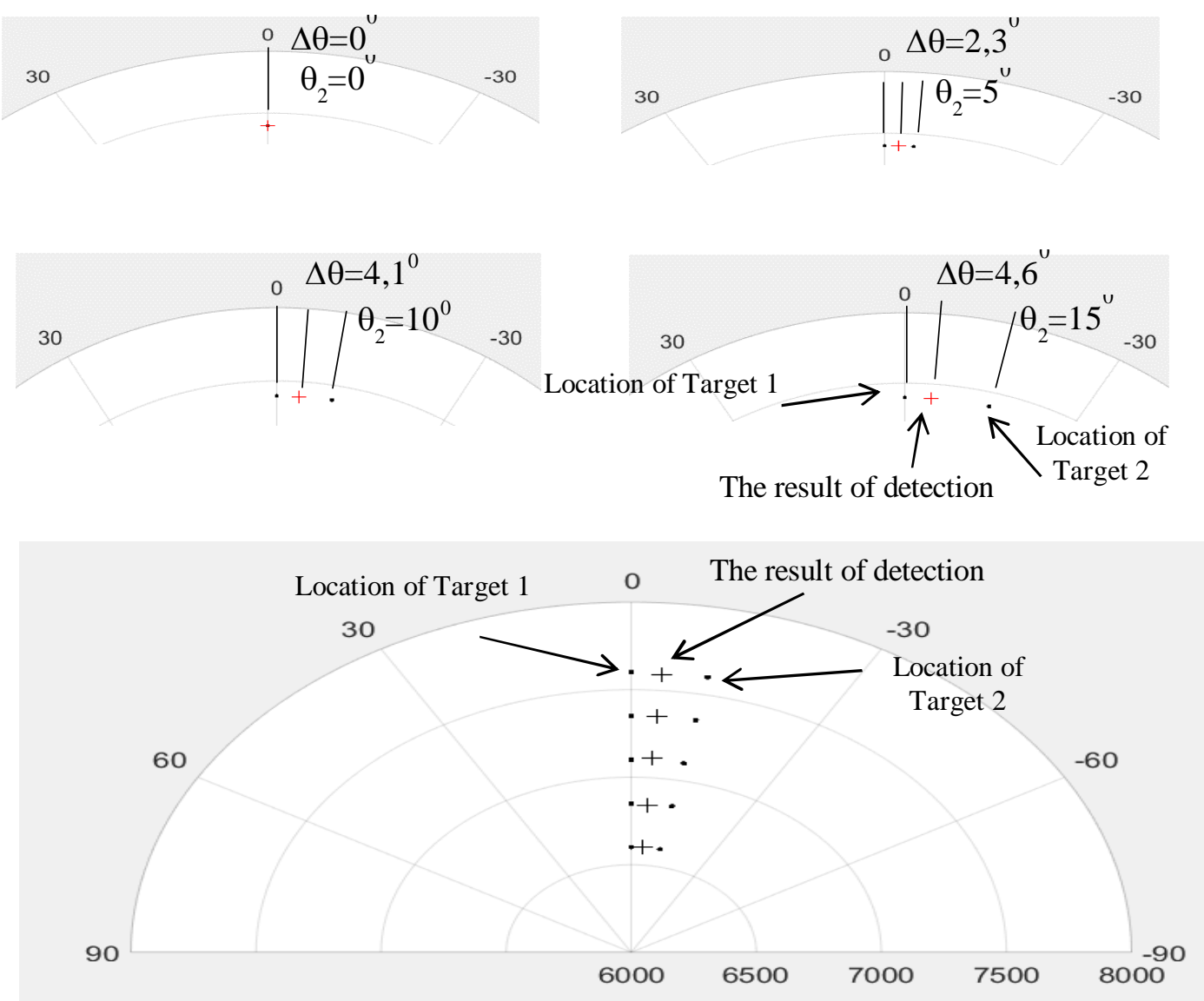

Figure 2: The results of measuring the azimuth of the target, which is located on the ESD, in the presence of the beam of the second target

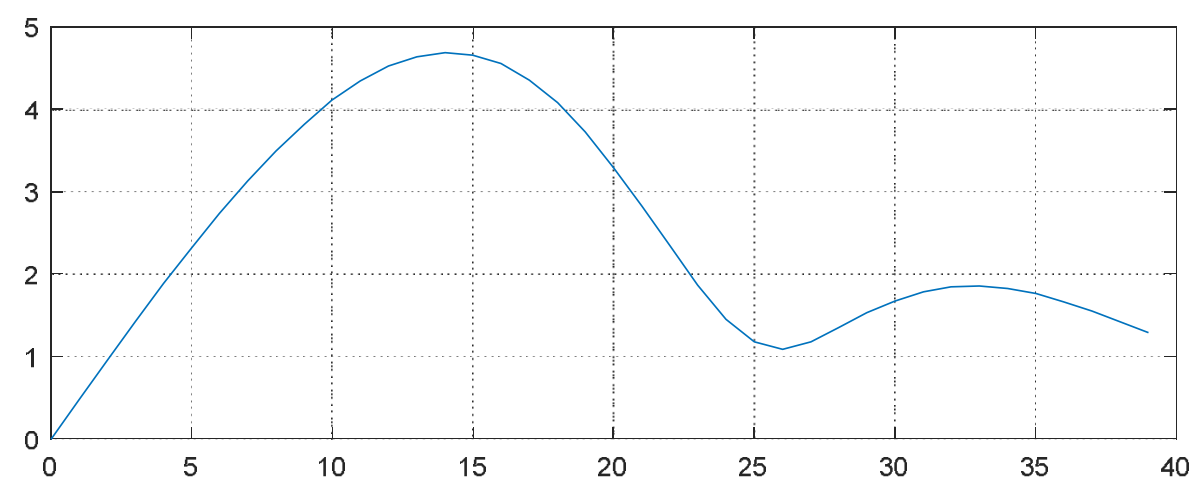

Figure 3 :The dependence of the measurement error of the azimuth of target 1, which is located on the ESD, on the position of target 2 
In Figure 3 shows that as the second target approaches the edge of the beam, the measurement error of the azimuth of the first target decreases. The increase in the azimuth measurement error after the mark $25^{0}$ is explained by the influence of the second target through the lateral lobe of the antenna orientation

Thus, from the analysis of Figure 1, Figure 2, Figure 3 it follows that insufficient azimuth resolution and high level of side lobes of the antenna pattern can lead to significant errors in determining the azimuth of the targets, accompanied by the presence in the beam of reflections from the underlying surface or reflections from other targets.

Thus, when simultaneously moving in the radial direction on the radar of two targets that are not separated by azimuth and released from two spatially spaced starting positions, one target will be detected with significant errors in determining the azimuth (Figure 2).

As a result, instead of the true position of the two starting positions, the wrong position of the wrong starting position will be determined. This can lead to a deterioration in the accuracy of information about the coordinates of the starting positions and disruption of the task.

According to the tactics and technical features of the simultaneous use of several AN/TPQ-49 radars in one position, they are located at a distance of at least $1 \mathrm{~km}$ from each other, as shown in Figure 4 [4].

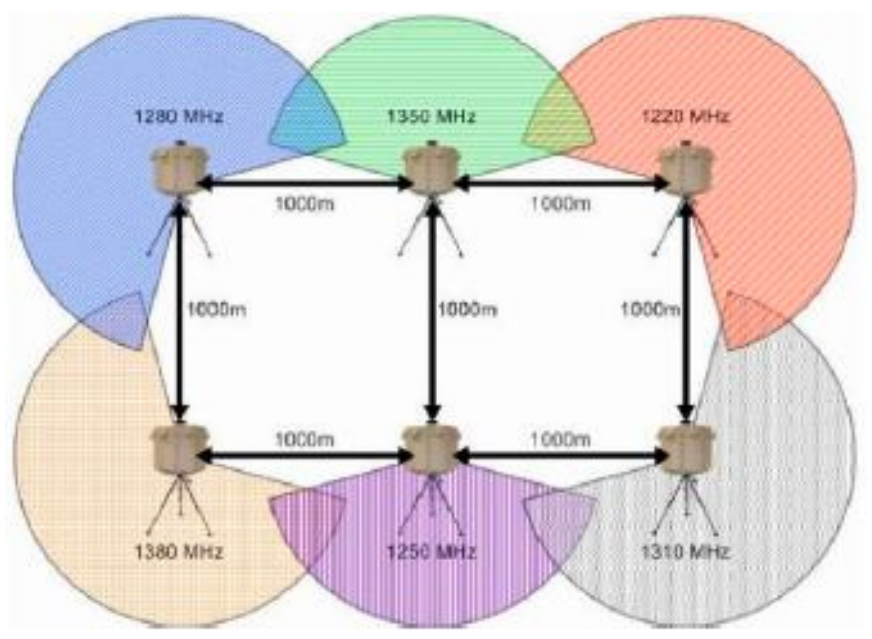

Figure 4 - The placing the radar AN / TPQ-49 while using in one position [4]

At the location of the radar, as shown in Figure 4, it is possible to use multi-position location methods to increase the azimuth resolution and reduce the effect of simultaneous presence in the beam of the antenna pattern of two inseparable targets on the accuracy of determining the azimuth of the target.
The possibility of using multi-position radar methods with the simultaneous use of several radars AN/TPQ-49 is due to the use in the radar of a modern element base and the following features of construction:

- the presence of a circular electronic scan provides the possibility of synchronous and coordinated survey of space by spatially spaced radars;

- the presence of digital transmitting, receiving and synchronizing systems provides the possibility of synchronous start and synchronous radiation of probing signals by spatially spaced radars.

Therefore, when combining spatially spaced radars into a multi-position system by implementing an additional system of synchronization and transmission of detected marks to a single processing point, it is possible to increase the accuracy and reliability of determining the coordinates of the starting positions.

In the two-position radar system, the root mean square error (MSE) of determining the azimuth of the target and the azimuth resolution in the implementation of the rangefinder method is determined by the expressions (3)-(4):

$$
\begin{gathered}
\sigma_{\beta}=\frac{\sigma_{\mathrm{R}} \sqrt{2}}{\mathrm{~L} \sin (\beta)}, \\
\Delta \beta \approx \frac{\Delta \mathrm{R}}{\mathrm{L} \sin (\beta)}=\frac{\mathrm{c}}{2 \mathrm{~L} \sin (\beta) \Delta \mathrm{f}_{\mathrm{c}}},
\end{gathered}
$$

where $\sigma_{R}-$ MSE range measurement; $\mathrm{L}$ - distance between radars; $\beta$ - azimuth of the target relative to the base line; $\Delta \beta$ - azimuth resolution; $\Delta \mathrm{R}$ - range resolution; $\Delta \mathrm{f}_{\mathrm{c}}-$ the width of the spectrum of the probing signal; $\mathrm{c}-$ the speed of light.

When the radar is located at a distance of $\mathrm{L}=1000 \mathrm{~m}$, providing appropriate synchronization for launch and inspection of space, the using of standard sounding signals (spectrum width $3 \mathrm{MHz}$ ) in directions perpendicular to the base line $\left(\beta=90^{\circ}\right)$ can be expected to provide azimuth resolution:

$$
\Delta \beta \approx \frac{\mathrm{c}}{2 \mathrm{~L} \sin (\beta) \Delta \mathrm{f}_{\mathrm{c}}}=\frac{3 \cdot 10^{8}}{2 \cdot 1000 \cdot \sin (90) \cdot 3 \cdot 10^{6}}=0,05(\mathrm{rad})=2,9^{\circ}
$$

In Figure 5, Figure 6 it shows the results of statistical modeling of determining the coordinates of targets in the system of two spatially spaced radars AN/TPQ-49 in the joint processing of the detected marks and the implementation of the long-range method. 
Hennadii Khudov et al., International Journal of Emerging Trends in Engineering Research, 8(9), September 2020, 5726 - 5732

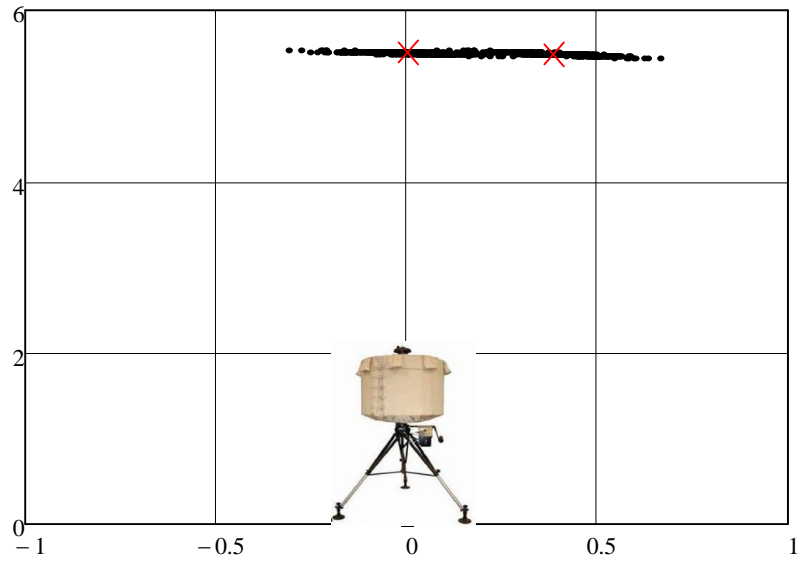

Figure 5 - The results of statistical modeling of the coordinates of targets by one radar AN / TPQ-49

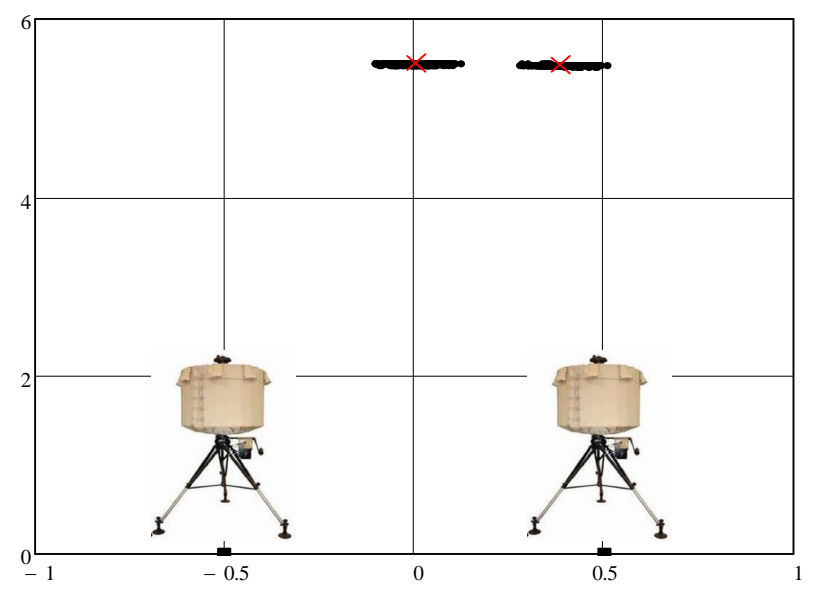

Figure 6 - The results of statistical modeling of the coordinates of targets by the system of two radars AN / TPQ-49, spaced at $1000 \mathrm{~m}$

Statistical modelling was performed for conditions when one target is located at a distance of $5.5 \mathrm{~km}$ and azimuth $0^{0}$ (relative to the origin), the second target is located at a distance of $5.5 \mathrm{~km}$ and azimuth $4^{0}$ (relative to the origin). In Figure 5 it shows that one radar AN/TPQ-49 detects these two targets as one target and cannot separate them by azimuth. When using a system of two radars AN/TPQ-49 and the implementation of the long-range method provides separation of targets and their separate observation (Figure 6).

\section{CONCLUSION}

Thus, when using several identical AN/TPQ-49 radars at the same position, which are located at a distance of at least $1000 \mathrm{~m}$, it is advisable to combine them into a multi-position system with synchronous start, coordinated survey of space and joint processing of detected marks. at the central point of radar information processing. This will complement the radar information obtained by each individual radar, the information that will be obtained from the joint processing using the rangefinder method.

As a result, it is expected to increase the azimuth resolution and reduce the error in determining the azimuth of the targets, which is due to the influence of the presence of several targets in the main beam of the antenna pattern. Increasing the resolution and accuracy of azimuth determination will increase the reliability of determining the coordinates of the starting positions.

\section{REFERENCES}

1. International Institute for Counter-Terrorism, URL: https://www.ict.org.il/\#gsc.tab=0 (accessed 22 August 2020).

2. M. Banasik, Armed Forces As The Russian Federation's Strategic Tool, Journal on Baltic Security, № 5 (2), 2019, pp. 1-12. DOI: https://doi.org/10.2478/jobs-2019-0008.

3. H. Khudov, S. Yarosh, V. Savran, A. Zvonko, A. Shcherba, P. Arkushenko The Technique of Research on the Development of Radar Methods of Small Air Objects Detection, International Journal of Emerging Trends in Engineering Research, Vol. 8. № 7, 2020, pp. 3708-3715. DOI: https://doi.org/10.30534/ijeter/2020/132872020.

4. Tactics, Techniques, And Procedures for Field Artillery Target Acquisition, 2012. 348 p. URL: https://www.trngcmd.marines.mil/Portals/207/Docs/TBS /MCRP\%203-16.1A\%20TTPs\%20for\%20Field\%20Artil lery\%20Target $\% 20$ Acquisition.pdf?ver=2015-06-08-144 125-603 (accessed 13 September 2020).

5. H. Khudov, I. Khizhnyak, I. Yuzova, O. Baranik, G. Semiv, S. Bondarenko, and O. Tytarenko. The Optimization Technique for Joint Discrete Search and Detection of Observation Objects, International Journal of Emerging Trends in Engineering Research, № 8(2), 2020, pp. 533-538. DOI: https://doi.org/10.30534/ijeter/2020/42822020.

6. V. Lishchenko, H. Khudov, B. Lisogorsky, O. Baranik, D. Holovniak, and O. Serdjuk The MIMO System on Based Existing Mechanical Rotation Radars with Wide Surveillance Area, in 2020 IEEE 40th International Conference on Electronics and Nanotechnology (ELNANO), 2020. P. 625-628. DOI: https://doi.org/10.1109/ELNANO.50318.2020.90887463

7. H. Khudov, A. Lykianchykov, D. Okipniak, O.Baranik, O. Ovcharenko, and N. Shamrai The Small Air Objects Detection Method on the Basis of Combination of Single-position and Different Receipt of Signals, International Journal of Emerging Trends in Engineering Research, № 8(8), 2020, pp. 4463-4471. DOI: https://doi.org/10.30534/ijeter/2020/68882020.

8. H. Khudov, I. Khizhnyak, V. Koval, V. Maliuha, A. Zvonko, V. Yunda, V. Nagachevskyi, and V. Berezanskyi The Efficiency Estimation Method of 
Hennadii Khudov et al., International Journal of Emerging Trends in Engineering Research, 8(9), September 2020, 5726 - 5732

Joint Search and Detection of Objects for Surveillance Technical Systems, International Journal of Emerging Trends in Engineering Research, Vol. 8. № 3, 2020, pp. 813-819.

9. M. Iasechko, V. Larin, D. Maksiuta, S. Bazilo, and I. Sharapa The method of determing the probability of affection of the semiconductor elements under the influence of the multifrequency space-time signals, Journal of Critical Reviews, Vol.7. № 9, 2020, pp. 569-571.

DOI: https://doi.org/10.31838/icr.07.09.113.

10. G. V. Khudov, Features of optimization of two-alternative decisions by joint search and detection of objects. Problemy Upravleniya I Informatiki (Avtomatika), 2003, № 5, pp. 51-59.

11. V. Lishchenko, H. Khudov, V. Tiutiunnyk, V._Kuprii, F._Zots, and G._Misiyuk. The Method of Increasing the Detection Range of Unmanned Aerial Vehicles In Multiradar Systems Based on Surveillance Radars, in 2019 IEEE 39th International Conference on Electronics and Nanotechnology (ELNANO), 2019. P. 559-562. DOI: https://doi.org/10.1109/ELNANO.2019.8783263.

12. H. Khudov, A. Zvonko, S. Kovalevskyi, V. Lishchenko, and F. Zots. Method for the detection of smallsized air objects by observational radars, Eastern-European Journal of Enterprise Technologies, № 2/9 (92), 2018, pp. 61-68.

https://doi.org/10.15587/1729-4061.2018.126509.

13. H. Khudov, A. Fedorov, D. Holovniak, and G. Misiyuk, Method of Radar Adjustment with Automatic Dependent Surveillance Technology Use, in Intern. Scient.-Pract. Conf. Problems of Infocommunications. Science and Technology (PIC S\&T), 2019, pp. 402-406. DOI:https://doi.org/10.1109/PICST47496.2019.9061245

14. I. Ruban, H. Khudov, V. Lishchenko, A. Zvonko, S. Glukhov, I. Khizhnyak, V. Maliuha, Y. Polonskyi, R. Kushpeta, The Calculating Effectiveness Increasing of Detecting Air Objects by Combining Surveillance Radars into The Coherent System, International Journal of Emerging Trends in Engineering Research, Vol. 8., № 4, 2020, pp. 1295-1301. DOI: https://doi.org/10.30534/ijeter/2020/58842020.

15. H. Khudov, A. Zvonko, I. Khizhnyak, V. Shulezko, V. Khlopiachyi, V. Chepurnyi, and I. Yuzova. The Synthesis of the Optimal Decision Rule for Detecting an Object in a Joint Search and Detection of Objects by the Criterion of Maximum Likelihood, International Journal of Emerging Trends in Engineering Research, № 8(2), 2020, pp. 520-524. $\quad$ DOI: https://doi.org/10.30534/ijeter/2020/40822020.

16. H. Khudov, S. Glukhov, O. Maistrenko, A. Fedorov, A. Andriienko, O. Koplik, The Method of ADS-B Receiver Systems Synchronization Using MLAT Technologies in the Course of Radar Control of Air Environment, International Journal of Emerging Trends in Engineering Research, Vol. 8. № 5, 2020, pp. 1946-1951.

17. V. Lishchenko, T. Kalimulin, I. Khizhnyak, and H. Khudov, The method of the organization coordinated work for air surveillance in MIMO radar, Paper presented at the 2018 International Conference on Information and Telecommunication Technologies and Radio Electronics, UkrMiCo, 2018 - Proceeding.

DOI: https://doi.org/doi:10.1109/ UkrMiCo43733.2018.9047560.

18. H. Khudov, A. Fedorov, D. Holovniak, and G. Misiyuk. Improving the Efficiency of Radar Control of Airspace with the Multilateration System Use, in Intern. Scient.-Pract. Conf. Problems of Infocommunications. Science and Technology (PIC S\&T), 2018, pp. 680-684. DOI: https://doi.org/10.1109/infocommst.2018.8632141.

19. H. Khudov, V. Lishchenko, B. Lanetskii, V. Lukianchuk, S. Stetsiv, and I. Kravchenko The coherent signals processing method in the multiradar system of the same type two-coordinate surveillance radars with mechanical azimuthal rotation, International Journal of Emerging Trends in Engineering Research, Vol. 8. № 6, 2020, pp. 2624-2630. DOI: https://doi.org/10.30534/ijeter/2020/66862020.

20. H. Khudov, V. Lishchenko, H. Hyshko, Y. Polonskyi, I. Khizhnyak, B. Riabukha, The MIMO Surveillance Radars System with High Accuracy Finding 2D Coordinates, International Journal of Emerging Trends in Engineering Research, Vol. 8. № 5, 2020, pp. 2026-2030. DOI: https://doi.org/10.30534/ijeter/2020/91852020.

21. V. Lishchenko, V. Chaliy, H. Khudov, and A. Zvonko. Proposals for Improving of Air Surveillance Informativity in MIMO Radar Systems Based on Two-Dimensional Radars, in Intern. Scient.-Pract. Conf. Problems of Infocommunications. Science and Technology (PIC S\&T), 2018, pp. 153-156. DOI: https://doi.org/10.1109/infocommst.2018.8632052.

22. H. Khudov, I. Khizhnyak, F. Zots, G. Misiyuk, and O. Serdiuk. The Bayes Rule of Decision Making in Joint Optimization of Search and Detection of Objects in Technical Systems, IJETER, № 8(1), 2020, pp. 7-12. DOI: https://doi.org/10.30534/ijeter/2020/02812020. 